\title{
Impact of Exchange Rate Fluctuation on Trade Value -Taking UK as an Example
}

\author{
Yinjie Chu \\ Shanghai University \\ SHU \\ Shanghai, China \\ canaanchu@126.com
}

\begin{abstract}
The main purpose of this paper is to study the impact of exchange rate fluctuations on UK exports during the UK referendum. Many scholars studied the impact in history, but they did not come to the same conclusion. Therefore, further research is needed. A metrological model is adopted in this paper. The dependent variable in this model is UK aggregate exports, and the explanatory variables are REER and UK total manufacturing output index. The result shows that with the background of the globalization of trade, the fluctuation of exchange rate has limited impact on aggregate exports.
\end{abstract}

Keywords-Aggregate Export; Exchange Rate Fluctuation; Manufacturing Output index; REER

\section{INTRODUCTION}

Due to the important impact of exchange rate on the macro economy of various countries, the research about exchange rate has always been the research target for all countries of government and scholars. However, the exchange rate system is also constantly changed along with the historical environment and in-depth research, and changed from fixed exchange rate to floating exchange rate system under management and finally the completely floating exchange rate system, and along with the opening of exchange rate "DOF", the impact of exchange rate on economy is constantly promoted, of which along with the global integration and the increasingly frequent trade among all countries, the position of exchange rate in international trade has also started to become decisive.

As one of the economic powers in European region, although it has entered into the European Union (at that time, it was European Economic Community) in 1973, UK always refused to join in Eurozone countries, and always independently issued pounds itself. One of the reasons why UK always refused to join in Eurozone countries is that UK can keep a stronger competitiveness in export trade, and meanwhile, possess autonomous financial policies. Besides, there was also the reason that UK always held that the relevant policies and future development trend of the European Union may damage the interests of UK. While after the financial crisis impact in 2008, European debt crisis burst in 2013, and all kinds of interest disagreements between UK and European Union member countries were obvious, making UK gradually lose its position and participation right in European Union.
Along with the release of the result of UK Brexit referendum on June 23, 2016, UK declared Brexit under the condition of $51.9 \%$, about RMB 15.7 million. This made the GBP-USD exchange rate for UK in the current day dropped sharply by about $11.7 \%$. After that, Brexit event was continuously leavened, and the GBP-USD exchange rate also created the minimum over 31 years. However, for this old brand economic power, it was not all bad news. In 1992, UK also similarly experienced a sharp devaluation of pounds; from September, 1992 to February, 1993, GBP-USD exchange rate was accumulatively decreased by $29 \%$, but during the same period, the export of commodities and services was increased by $45 \%$ on the contrary. However, from 2008 to 2009, the global economy and trade were impacted by the financial storm of America, caused the drastic fluctuation of exchange rate, while GBP was accumulatively subject to $8.4 \%$ of devaluation; meanwhile, the export and import trade were respectively decreased by $12.66 \%$ and $12.13 \%$ during the same period.

Generally, we divide the impact of exchange rate fluctuation on trade value into two forms, and the first form is the impact of horizontal variations in exchange rate on the trade value, and the other one form is the impact of exchange rate fluctuation on trade value. However, under the current research, theories about the impact of horizontal variation for exchange rate, i.e., the devaluation or appreciation of one country's currency on trade have been developed relatively matured, and mainly include Marshall-Lerner Condition and $\mathrm{J}$ curve theory. Relatively, the impact of exchange rate fluctuation on trade value has the divergence in research. Through starting from the attitude of export enterprises about risks, as a rational person, export should be decreased under the condition of the risk of increase in exchange rate. Through starting from the perspective of regarding export as a kind of real option, along with the increase in exchange rate fluctuation, within the range regarded by enterprises with avoidable risks, profit-making opportunities are increased, so enterprises will increase export. Thus, it is necessary to continuously study the impact of exchange rate fluctuation on trade value. Therefore, what did the sharply dropped exchange rate brought by UK Brexit in 2016 to the export of UK commodities and services, promotion effect or restriction effect? Under such background, it has an important meaning to 
study the impact of GBP exchange rate on UK trade port volume.

\section{BRIEF INTRODUCTION ABOUT THE EXCHANGE RATE SYSTEM OF UK}

As early as 1694, GBP was issued by the Bank of England as the standard currency of UK. In 1821, UK introduced gold currency standard system, and regarded GBP as the standard currency unit, and the nominal gold content per GBP was $7.32238 \mathrm{~g}$, however, along with the explosion of the World War I in 1914, gold standard system was disassembled soon after the start of wartime protection mechanism in various countries, and as the main force of the Entente countries, UK also abolished gold standard system. along with the end of World War I, economy was operated again; In May, 1925, UK executed gold bullion standard system, but gold bullion standard system was not continued, and along with the start of Economy Great Depression in America, UK was forced to give up the gold bullion standard system exchange rate system, and then GBP became inconvertible paper currency. Meanwhile, in consideration of the foreign exchange management and control demands, UK still stipulated that the gold content for GBP shall be 3.58134g [1] on December 18, 1946.

During the period when World War II broke out, as the belligerent state, UK executed strict foreign exchange management system again, and its exchange rate was fixed at $\$ 4.03 / \&$. Along with the end of World War II, UK cancelled foreign exchange control and then implemented free convertibility on July 15, 1947, but along with the fast loss of UK foreign exchange reserves incurred by such radical exchange rate form, so in August of the same year, it was also recovered to foreign exchange control. After that, GBP declared devaluation for two times in 1949 and 1967 respectively, and in 1967, it was devalued to USD 2.40; meanwhile, it also adjusted the gold content of GBP (2.13281g). After USD floating exchange rate was implemented in August, 1971, UK took the unchanged gold content as the foundation to confirm the rate of exchange against USD. After America declared devaluation in the same year, UK declared that the new exchange rate for converting GBP into USD was $\$ 2.6057 / \&$. Meanwhile, the actual exchange rate can be fluctuated within GBP 1 for the conversion of USD 2.5471-USD 2.6643, and the fluctuation range was about $4.5 \%$. In January, 1974, along with the relevant exchange rate policy of UK being completed, the actual exchange rate of GBP became the floating exchange rate system under management. In the same year, pound sterling area shrunk, and merely included UK, Ireland, Cayman Islands and Channel Islands. The gold reserves issued by GBP were equivalent to at least above GBP 2.65 billion. On October 8, 1990, GBP joined in European Currency System, and the fluctuation range about the exchange rate against all kinds of currency inside the currency system was 6\%. On September 16, 1992, UK declared that GBP was temporarily separated from European Currency System [2].

\section{IMPACT OF EXCHANGE RATE FLUCTUATION ON TRADE VALUE}

The influence of exchange rate appreciation or devaluation on trade volume has relatively mature theoretical development, which mainly includes the Marshall-Lerner conditions and J-curve effect relevant theories mentioned above. The demonstration part of the paper mainly focuses on the influence of exchange rate variations on the export of UK, while Marshall-Lerner conditions and J-curve effect relevant theories are conducive to understanding the influence of exchange rate on the international trade volume variations.

What Marshall-Lerner conditions indicate is the flexible analysis method of currency devaluation in the international balance of payments, and if one country is in Marshall-Lerner conditions, it will cause the devaluation of domestic currency, while the devaluation of domestic currency causes the improvement of trade deficit, and should be generated when the import and export demand elasticity sum is bigger than 1 . This theory is mainly based on four points of assumptions [3], 1) under the condition that other trading conditions are not changed, only the exchange rate is changed; 2) without considering the mobility of international capital, and merely regard trade balance as the balance of international payment; 3 ) the supply elasticity for trade goods is infinitely great; 4) during the start, i.e., before exchange rate fluctuation occurs, international trade is under a balanced status, during which if we assume $\eta_{X}$ is the export elasticity, and $\eta_{M}$ is the export elasticity, under Marshall-Lerner conditions, there will be:

When $\eta_{X}+\eta_{M}>1$, the devaluation of domestic currency will improve trade balance, otherwise the appreciation of domestic currency will worsen trade balance;

When $\eta_{X}+\eta_{M}=1$, no matter which kind of horizontal variations occurs to the domestic currency, there is no influence on trade balance;

When $\eta_{X}+\eta_{M}<1$, the devaluation of domestic currency will deteriorate trade balance, otherwise the appreciation of domestic currency will improve the trade balance conditions on the contrary.

Under the assumption of Marshall-Lerner conditions when the foreign exchange market is stable, it is applicable to analyze how the horizontal variations of exchange rate influences the trade balance conditions of a country within a long time [4]. However, in the international trade, the mode of signing trade contract is adopted for conducting goods import and export trade. If the domestic currency is suddenly subject to devaluation, during the initial period of devaluation, the flexibility for the imported and exported goods volume is relatively small, and foreign currency is mostly adopted for foreign currency, and this will cause the sudden decrease in the export amount of a country; meanwhile, the speed for the price of imported goods to be changed with the change of exchange rate is also faster than the changes in price of exported goods, so this will make the trade balance of a country deteriorate within a short time. However, as can be seen from the long term, various trade companies will adjust the contract involved, and cause the price adjustment of exported goods and service, and then improve trade balance. [5] Thus, under the currency 
devaluation conditions of a country, the trade balance will deteriorate within a short time, and in a long term it will be improved, but it is merely reflected as a J-shaped curve on coordinate graphs, and the exchange rate variation effect obtained thereby should be called as J-curve effect [6].

\section{Empirical research}

Based on the aforementioned theories, this paper assumes (1) the price level for domestic and overseas goods is merely influenced by the exchange rate, and other conditions are kept unchanged; (2) the market of one country is under fully competitive status, and the export manufacturers of one country is generally the accepter of price, and the influence of exchange rate on international trade is continuous.
The model of this paper can be designed accordingly as: $y_{U K}=\alpha+\beta_{1} E R_{U K}+\beta_{2} M I_{U K}+\epsilon$

Of which, $\alpha$ is the intercept of the model, $y$ is the general export index of UK $\left(y_{1990 U K}=100\right.$, and the data index afterwards are similar); $E R_{U K}$ is the real effective exchange rate index of $\mathrm{UK} ; M I_{U K}$ is the gross output index of manufacturing industry in UK and $\epsilon$ is the random fluctuation item.

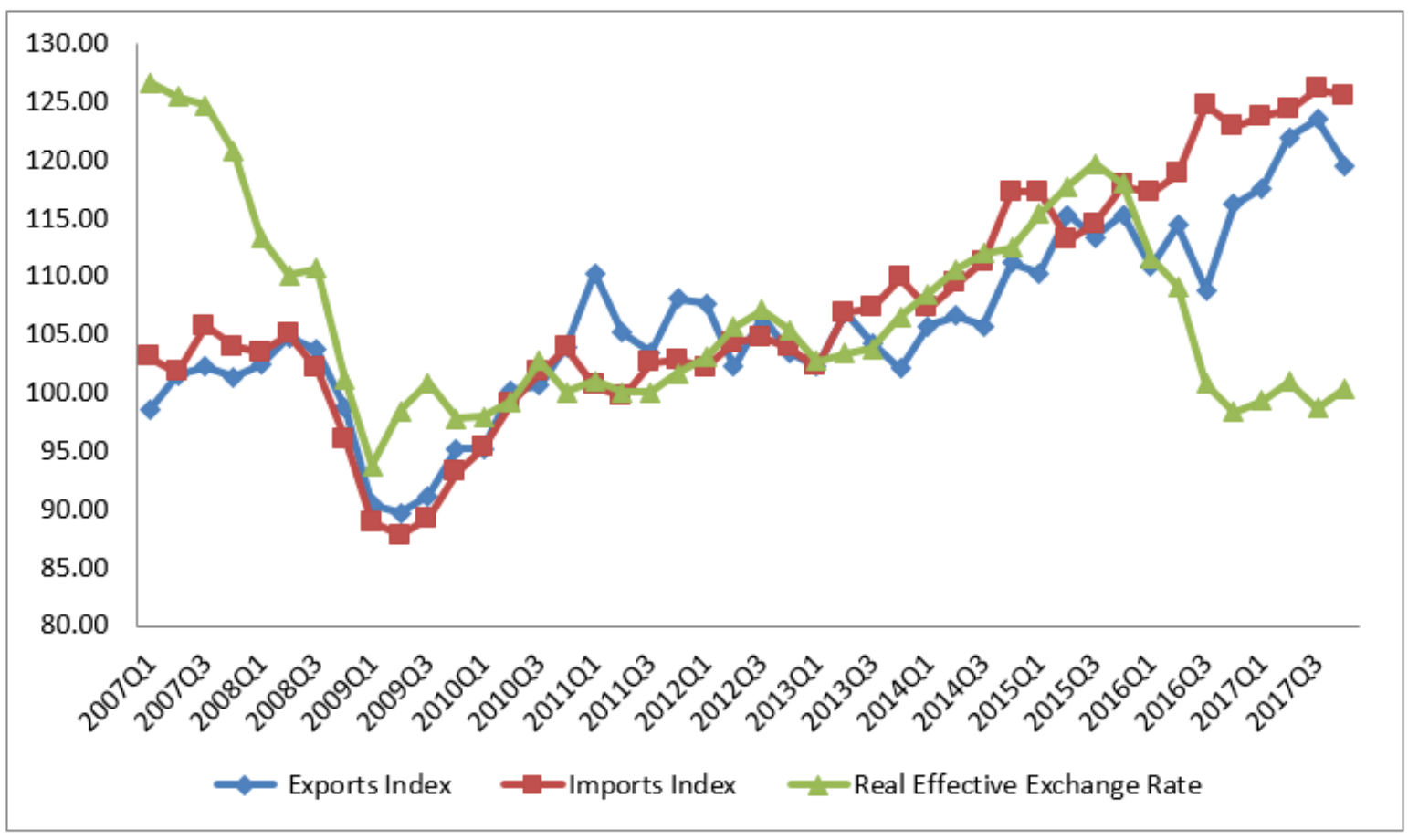

Fig. 1 British Exports, Import \& REER Index

As per the previous theories, during UK Brexit, our expectation for the model is that: the first item $\beta_{1}$ is a positive value, and since the exchange rate has been subject to indexation, along with the devaluation of GBP, export will be increased; but during the financial crisis, the first item $\beta_{1}$ may be a negative value, i.e., along with the devaluation of GBP, decrease will occur similarly. The second item $\beta_{2}$ is a positive value, and along with the improvement of domestic industrial production index in UK, the domestic production capacity in UK will be improved, and along with the improvement of production capacity, the domestic market of UK will be gradually saturated, so in production, it will seek for conducting the export of goods in the international market, so the improvement of industrial production index will exert overflow effect on the export amount, so the export will also be improved.

The data adopted in this paper are the quarterly data of 11 years from 2007 to 2017, and in order to decrease the abnormal fluctuation of data, and ensure the data uniformity in the research process, the data involved in the model research process are from the database of International Financial Statistics for IMF, and the same basic year is adopted for indexation, of which the real effective exchange rate of UK is subject to CPI index processing through nominal exchange rate, and after deducting the inflation factor, the real effective exchange rate of UK can be obtained, and then on the basis of the same basic year, it can be obtained through indexation.

As per the data display of IMF World Bank, just as mentioned before, the changes reflected in the export and import trade of UK during the two times of exchange rate devaluation was largely different, and during financial crisis, within the GBP devaluation period from the start of the first quarter of 2007 to the end of the second quarter of 2012, UK import and export trade was subject to the decrease of import and export quantity along with GBP devaluation, and during Brexit period, within GBP devaluation period from the third quarter of 2012 to the fourth quarter of 2017, the import and 
export trade in UK was subject to the increase of import and export quantities along with GBP devaluation.
As per the model, conduct least square regression for the data from the first quarter of 2007 to the second quarter of 2012, and then obtain the following regression result:

TABLE I REGRESSION STATISTICS 2007Q1-2012Q2

\begin{tabular}{|l|l|}
\hline Regression Statistics & 0.5399 \\
\hline Multiple R & 0.2915 \\
\hline R Square & 0.2426 \\
\hline Adjusted R Square & 4.6241 \\
\hline Standard Error & 22 \\
\hline Observed Value & \\
\hline
\end{tabular}

TABLE II REGRESSION RESULTS 2007Q1-2012Q2

\begin{tabular}{|c|c|c|c|c|}
\hline & Coefficients & $\begin{array}{c}\text { Standard } \\
\text { Error }\end{array}$ & t Stat & P-value \\
\hline$\alpha$ & 12.9982 & 25.8874 & 0.5021 & 0.6194 \\
\hline$E R_{U K}$ & -0.3345 & 0.1879 & -1.7806 & 0.0855 \\
\hline$M I_{U K}$ & 1.2578 & 0.4096 & 2.0708 & 0.0046 \\
\hline
\end{tabular}

As per the result obtained thereby, during the period of financial crisis, $\mathrm{R}$ square and the adjusted $\mathrm{R}$ square value are all under 0.2915 and 0.2426 , which can make the relevant regression result possess certain credibility, of which the coefficient of real effective exchange rate is -0.3345 , which means that when other conditions are not changed in UK, GBP devaluation will make the export trade volume of UK decrease accordingly. Similarly, the coefficient of industrial production index is 1.2578 , and this indicates that along with the increase of industrial production index, i.e., the promotion of industrial productivity, the export trade volume of UK will also be increased accordingly.

Similarly, as per the model, conduct least square regression for the data from the third quarter of 2012 to the fourth quarter of 2017, and then obtain the following regression result:

TABLE III REgRESSION STATISTICS 2012Q3-2017Q4

\begin{tabular}{|l|c|}
\hline Regression Statistics & 0.5715 \\
\hline Multiple R & 0.2595 \\
\hline R Square & 0.2341 \\
\hline Adjusted R Square & 3.2722 \\
\hline Standard Error & 22 \\
\hline Observed Value & 22 \\
\hline
\end{tabular}

TABLE IV REGRESSION RESULTS 2012Q3-2017Q4

\begin{tabular}{|c|l|l|c|c|}
\hline & Coefficients & Standard Error & t Stat & P-value \\
\hline$\alpha$ & -14.8798 & 3.4831 & -3.8385 & 0.0011 \\
\hline$E R_{U K}$ & 0.1574 & 0.1110 & 0.5169 & 0.6112 \\
\hline$M I_{U K}$ & 1.4856 & 0.3265 & 2.6120 & 0.0000 \\
\hline
\end{tabular}

Similarly, as per the result obtained through regression, during the period of UK Brexit, $\mathrm{R}$ square and the adjusted $\mathrm{R}$ square value are all under 0.2595 and 0.2341 , which can make the relevant regression result possess certain credibility. During the period, the coefficient of real effective exchange rate is 0.0574 , which means that when other conditions are not changed, GBP devaluation will generate certain positive influence on the export trade of UK, and during the period, the coefficient of industrial production index is 2.4856 , and the influence of industrial production index on the export trade volume of UK is similar.

During the period, we compare three groups of data, including the total export conditions of UK, the industrial production index and the real effective exchange rate, as can be seen from the figure, during the financial crisis, since the global economy is influenced by American subprime mortgage crisis, UK industrial production index is also subject to 
cliff-typed decrease, so from the perspective of export manufacturers, under the condition that the self-supply capacity and market demand are insufficient, the export volume will be naturally decreased accordingly, during the period, the exchange rate will be under the influence similar to American subprime mortgage crisis, so relatively big scale of decrease will occur, so as can be seen from the aforementioned two points, within the special period of financial crisis, the influence of the fluctuation of GBP exchange rate on the export volume of UK isn't the main factor, and within such period, the main influencing factors for the export of UK is the industrial production capacity of UK.

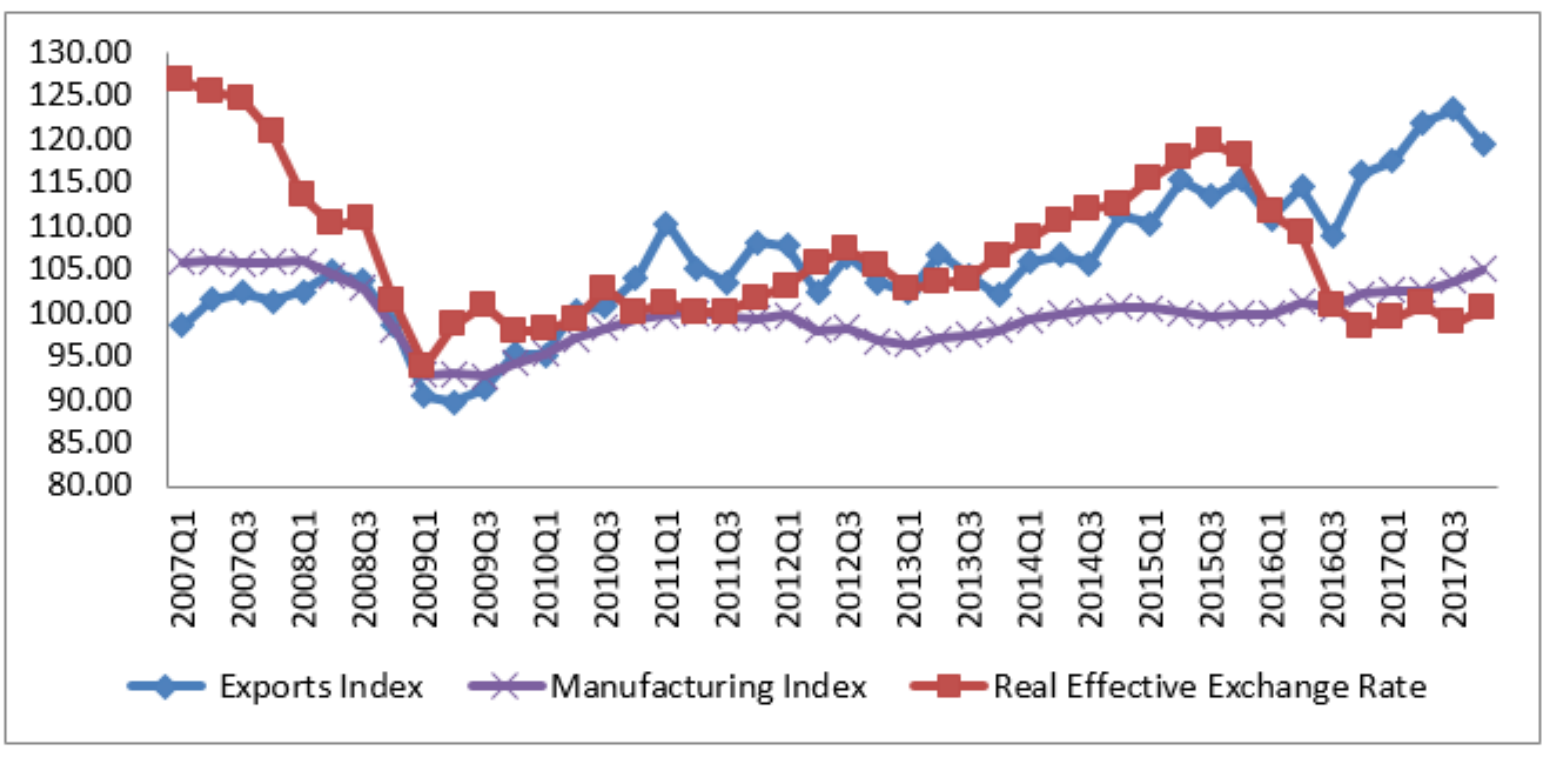

Fig. 2 British Exports, Manufacturing \& REER Index

Within the period for UK Brexit, the changes in the industrial production capacity of UK was relatively stable, and the average floating rate of change was within $0.50 \%$, but within the period to launch referendum and the period when referendum is completed, the average devaluation of GBP was $1.54 \%$, during the period, the accumulated devaluation was about $17.83 \%$, and at that time, the export trade volume of UK was averagely increased by $0.42 \%$, and accumulatively increased by $13.43 \%$ under the condition that the domestic industrial production capacity of UK was relatively stable.

To sum up, the influence of exchange rate change on export trade is relatively restricted, and in combination with the previous theories, the reasons causing such phenomenon can be ascribed to the background of contemporary globalization, and the modernized supply chain is constantly complicated and internationalized, and during the export process of export countries in various countries worldwide, there are also certain proportion of import, i.e., a final finished product is also produced by the imported parts of various countries. For international buyers, the bid price for finished goods during GBP devaluation was relatively cheap, but for the local manufacturers in UK, the production cost in the earlier stage will be improved with the devaluation of GBP, so for manufacturers, the advantages obtained during the devaluation period of GBP in product were also weakened due to cost increase.

\section{CONCLUSION}

As for the devaluation of GBP incurred by UK Brexit, on the surface, it has indeed generated certain positive influence on export, but under the current background of international trade globalization, the thought of using the expected exchange rate depreciation to increase export trade is a kind of improper competitive strategies that can benefit oneself at others' expense, and the active influence brought by such strategy is merely a flash in the pan, and cannot fundamentally change the international trade conditions of a country. In order to improve the international trade conditions, firstly, it is requested to further improve its own industrial structures; secondly, it is requested to decrease trade protectionism and trade barrier setup, and finally, reinforce the research of scientific technology, so as to decrease the production cost of goods and even provide more competitive commodities. Through these approaches, active influence can be brought to the international trade conditions of a country, and in a long term, such active influence will be converted to essential promotion. 


\section{REFERENCES}

[1] Pound-complex [J]. Financial Economics. Ge Lin. 2005.06. P44-45.

[2] Function of World's Currency-USD and Its Development Trend [J]. Wang Xin and Cao Kang. Economic Research Guide. 2012. Period 10. 85-87.

[3] Influence of RMB Actual Exchange Rate Level and Fluctuation on the Import and Export Trade [J]. World Economy Study. Cao Yang and $\mathrm{Li}$ Jianwu. 2006. Period 8. P56-59.

[4] Chen Zhiang. Empirical Research about RMB Exchange Rate and the Export Variations of Zhejiang [J]. Chen Zhiang. Business Economics and Administration. 2001, Period 04. P45-50.

[5] Influence of Exchange Rate Fluctuation on Trade Flow [J]. Zhang Meixia. Journal of the University of International Business and Economics. 2003.06. P27-31.

[6] Theoretical and Empirical Study about Chinese Trade Surplus and RMB Exchange Rate Adjustment [D]. Lai Xianling. Ningbo University. 2009.

[7] Influence of Exchange Rate Fluctuation and External Demand Variation on the Export of Shandong Province [J]. Si Chuanning and Liu Qinglin. Shandong Social Science. 2012. Period 04. P145-148. 